\title{
POPULISMO E DEMOCRACIA LIBERAL NA AMÉRICA DO SUL ${ }^{1}$
}

\author{
Héctor Ricardo Leis
}

\begin{abstract}
Resumo
O populismo é um fenômeno contraditório. As singularidades que marcam sua história na América do Sul mostram isto. Este trabalho procurará registrar a diversidade de circunstâncias que compõem os países da região, para posteriormente concentrar seus esforços na análise do populismo. As conclusões do trabalho vão além dos particularismos do fenômeno populista, associado tanto a regimes autoritários como democráticos, sejam de esquerda ou de direita, mostrando sua convergência numa cultura produtora de antagonismos que derivam irremediavelmente na decadência da comunidade política como um todo. Neste sentido, o principal efeito do populismo será emperrar as instituições próprias da democracia liberal.
\end{abstract}

Palavras-chave: Populismo; Democracia Liberal; América do Sul; Economia de Mercado; Estado de Direito.

\begin{abstract}
Populism is a contradictory phenomenon. Great singularities mark its history in South America. This paper will try to register the diversity of circumstances that applies to the countries of the area, for later on to concentrate its efforts in the analysis of the populism. The conclusions go beyond the particularities of the populism, phenomenon associated so much to authoritarian regimes as to democratic ones, in the left or right wings, with a cultural convergence in favor of antagonisms that produce a decadence of the political community as a whole. In this sense, the main effect of the populism is to hinder the institutions of liberal democracy.
\end{abstract}

Key-works: Populism; Liberal Democracy; South America; Market Economy; Rule of Law.

\section{América do Sul no inicio do século 21}

A América do Sul manifesta um importante retraso relativo com relação aos países emergentes de outras regiões. Esta circunstância se explica pelo bloqueio das reformas pró-mercado na maioria dos países do subcontinente; a erosão do Estado de Direito; a degradação da qualidade da democracia; e a extensão da criminalidade de todo tipo (aproximadamente 30 de cada 100.000 pessoas são assassinadas com

\footnotetext{
1 Artigo apresentado originalmente no $6^{\circ}$ Encontro da ABCP (2008), área temática de Cultura Política e Democracia. Nos nomes de José Álvaro Moisés e Marcelo Baquero, agradeço a todos os membros da área que debateram e contribuíram para o desenvolvimento melhor dos temas aqui presentes. Agradeço muito especialmente a Eduardo Viola pela utilização de trabalho de pesquisa conjunto.
} 
armas de fogo, cifra três vezes maior que a média mundial) (WHITEHEAD, 2006; O'DONNEL, 1999; VIGEVANI e OLIVEIRA, 2005). Para compreender consistentemente a dinâmica da América do Sul é necessário partir de uma análise diferenciada da evolução dos países nos anos transcorridos desde o fim da guerra fria, com o objetivo de avaliar quanto cada um se aproximou do modelo de economia de livre mercado, Estado de Direito e democracia liberal-representativa, já que a experiência internacional mostra que os países realizam suas metas através da convergência dessas instituições. A seguir, uma síntese dos países de América do Sul, listados segundo seu grau de modernidade econômica e política.

o Chile é o único país que realizou dramáticos progressos, tendo ascendido fortemente no sistema internacional, crescendo $6 \%$ ao ano nos últimos 20 anos. Em 2006, o Chile tinha uma população de 16 milhões de habitantes, um PIB de 150 milhões de dólares (220 em Paridade de Poder de Compra - PPP) e um PIB per capita de 9.000 dólares (13.500 dólares em PPP) ${ }^{2}$. A economia de livre mercado e suas instituições introduzidas pela via ditatorial durante a década de 1980 se consolidaram com a democracia na década de 1990: banco central independente, equilíbrio fiscal, câmbio livre e flutuante, altíssima abertura ao comércio internacional, regime de aposentadoria de capitalização, cumprimento muito rigoroso e rápido dos contratos em todas as decisões do judiciário (TALAVERA, 2004). A democracia iniciada com as primeiras eleições livres em 1990 foi se consolidando até a plena subordinação dos militares ao poder civil e as disputas eleitorais oscilarem em torno de sólido consenso compartilhado pelos principais partidos políticos sobre os fundamentos da ordem econômica e social. Apesar do Chile ter sofrido um dos golpes mais sangrentos em 1973, o peso das suas instituições republicanas ajudou que o regime de Pinochet estabelecesse uma transição pautada democraticamente através de plebiscito, caso único na região. O Chile também reforçou em todos os planos o Estado de Direito, conseguindo impedir o crescimento da criminalidade que assola o resto do subcontinente. Com esse gigantesco

${ }^{2}$ Os dados de Chile e países seguintes foram tomados de Viola e Leis (2007, p. 173-197).

REVISTA DEBATES, Porto Alegre, v. 2, n. 2, p. 25-47, jul.-dez. 2008. 26 
avanço, o Chile tem uma dinâmica de integração global antes que regional.

O Brasil é o segundo país em progresso modernizador, mesmo que muito atrás do Chile, crescendo apenas 2,5\% ao ano nos últimos 15 anos. Em 1990, era um país sem moeda, com superinflação crônica, com uma economia com fortes controles estatais e muito fechada ao mundo e com uma democracia incipiente. A dinâmica da última década e meia tem sido contraditória. Do lado positivo atingiu-se a estabilidade monetária, os preços e o câmbio foram significativamente liberalizados, a economia se abriu moderadamente ao comércio internacional, várias empresas estatais foram privatizadas, a maioria das empresas privadas se adaptou bem ao desafio da globalização, um banco central cada vez mais independente consolidou um moderno sistema de metas de inflação, aumentaram as reservas, criaram-se agências reguladoras com o objetivo de insular as estruturas regulatórias dos políticos e houve alternância no poder nas eleições de 2002. Do lado negativo, continuou significativamente alta a dívida pública (especialmente a interna) e a carga tributária, o regime de aposentadorias apresenta desequilíbrios crescentes com tendências catastróficas, a legislação trabalhista permanece obsoleta (levando $60 \%$ dos trabalhadores a ficar fora do mercado formal), a corrupção continua alta e a criminalidade tem crescido exponencialmente. Em 2006, o Brasil tinha uma população de 186 milhões de habitantes, um PIB de 900 milhões de dólares $(1,7$ trilhão em PPP) e um PIB per capita de 4.900 dólares (9.000 dólares em PPP).

A Argentina teve um desempenho ciclotímico, já que houve progresso significativo no plano das reformas econômicas e abertura ao mundo no período 1991-96, mas houve um gigantesco declínio político desde 1999, causado pela não transformação da suas instituições políticas, que favorecem o populismo e a corrupção. Esse processo de declínio tem uma fase mais aguda no período 2001-02. O governo Kirchner, iniciado em 2003, aproveitou muito bem a janela de oportunidades no sistema internacional e reestruturou a dívida externa com um desconto altíssimo do valor face. A Argentina tinha em 2006 
uma população de 39 milhões de habitantes, um PIB de 220 bilhões de dólares (540 bilhões em PPP) e um PIB per capita de 5.500 dólares (16.000 em PPP). A credibilidade da Argentina entre os investidores internacionais continua sendo muito baixa, mas o dinheiro de propriedade de argentinos, que estava fora do país ou do sistema bancário, tem retornado em escala importante, promovendo novos investimentos em setores como construção civil e têxtil, mas não nos setores de maturação de longo prazo, como infra-estrutura e energia. A alta taxa de crescimento tem dado ao presidente Kirchner legitimidade para centralizar significativamente o poder criando as condições para o estabelecimento de um sistema de partido hegemônico seguindo a tradição peronista. O MERCOSUL favoreceu bastante a expansão do comércio internacional do país desde sua fundação até a desvalorização do real em 1999, mas a partir desse ano a perda crescente de competitividade de suas empresas levou o país a agir num sentido crescentemente protecionista, erodindo as regras de jogo do bloco.

O Uruguai ficou estagnado no que se refere às instituições econômicas, com a excessiva presença do Estado e um regime de aposentadoria que agravou os problemas da pirâmide demográfica envelhecida; e, no relativo às instituições políticas, há um sistema partidário com fortes componentes clientelísticos, que aumentou exponencialmente o gasto público. Isto levou a uma profunda crise econômica e social em 2002, similar à da Argentina, mas com uma resposta oposta à desse país, já que todos os contratos foram honrados. Os anos 2003-04 implicaram um poderoso ajuste fiscal que teve como conseqüência um forte crescimento da preferência pela esquerda no eleitorado. Esta venceu as eleições de 2005, mas, contra algumas previsões, iniciou um governo de esquerda moderna na trilha chilena. Contrariamente às expectativas de suas principais lideranças, a participação do Uruguai no MERCOSUL não tem favorecido a expansão de sua corrente de comércio e foi se acumulando uma decepção crescente com Argentina, em função da crise das plantas de celulose no Rio Uruguai, assim como com a omissão brasileira a respeito. 
No Peru, tem havido crescimento econômico continuado a taxas superiores a 5\% ao ano desde 1993 e houve construção de algumas instituições econômicas modernas - regimes fiscal, cambial, de investimentos estrangeiros e de aposentadoria, grande crescimento da corrente de comércio - mas num contexto de baixa irradiação para a massa popular e forte corrupção política, primeiro sob o regime autoritário de Fujimori e depois na presidência democrática de Toledo (TANAKA, 2005). Mas com Alan Garcia, o Peru parece ter encontrado nos últimos anos o caminho para o crescimento econômico com diminuição da pobreza. Com uma grande diáspora morando nos EUA e sendo uma parte importante de sua pauta de exportações competitivas no mercado americano, o interesse nacional do Peru aponta muito mais para o norte que para o sul das Américas.

A Colômbia é um país peculiar na América do Sul por três razões: um estatismo menor que no resto do subcontinente; partidos dominantes relativamente não populistas; e uma violência endêmica desde fins da década de 40, que na década de 60 se desdobrou numa poderosa guerrilha comunista rural (de inspiração castrista e maoísta) e também em redes de narcotráfico, que na década de 1980 se tornariam poderosos cartéis internacionais. Apesar de tudo isso, a Colômbia manteve uma taxa de crescimento econômico contínuo (em parte derivado do ingresso de divisas do narcotráfico). Em 2006, o país tinha uma população de 46 milhões de habitantes, um PIB de 120 bilhões de dólares (390 dólares em PPP) e um PIB per capita de 2.600 dólares (8.300 dólares em PPP). As instituições se deterioram progressivamente até 2002 devido à tolerância e acomodação dos partidos dominantes, em parte apoiadas pela União Européia (BEJARANO e PIZARRO, 2005). A eleição e reeleição do conservador Uribe para a presidência, com uma proposta de combate radical a guerrilheiros e narcotraficantes (intimamente vinculados desde o fim da década de 1990) e apoiado pelos EUA, está revertendo a decadência colombiana (hoje Bogotá, Medellín e Cali têm índices de homicídios inferiores a Rio de Janeiro e São Paulo, embora a guerrilha mantenha ainda territórios rurais sob seu controle). 
A Venezuela é um caso de profunda e continuada decadência política (corrupção sistêmica baseado nas oligarquias partidárias até 1998 e no populismo plebiscitário com Chávez desde 1999) e social (extrema dependência do Estado de vastos setores sociais) (COPPEDGE, 2005). Em 2006, o país tinha uma população de 27 milhões de habitantes, um PIB de 190 milhões de dólares (igual em PPP) e um PIB per capita de 7.000 dólares (também igual em PPP). A partir da consolidação do chavismo no plebiscito de 2004, a Venezuela passou a se comportar, no sistema internacional, como um ativo questionador dos valores e interesses das democracias de mercado, em particular dos EUA, inclusive colocando recursos crescentes na exportação da revolução bolivariana em escala regional (interferência com diversos graus de eficácia em processos eleitorais na Bolívia, no Peru, no Equador, na Nicarágua, na Guatemala e no México). Contudo, a economia venezuelana continua sendo muito aberta comercialmente e muito dependente das exportações de petróleo para os EUA. A combinação de alto preço do petróleo com forte acumulação de poder pessoal tem dado a Chávez uma capacidade inusitada de intervir na política latino-americana e inclusive mundial, não prevista por nenhum analista no início do regime. A reeleição de Chávez em dezembro de 2006 foi num contexto livre (com pequenas restrições) e gerou condições para um aprofundamento dos componentes anticapitalistas do seu regime bolivariano, que começaram a efetivar-se com propostas de nacionalizações nas áreas de energia, siderurgia, cimento e telecomunicações, entre outras.

O Equador tem sido o país mais instável politicamente da região na última década, com todos os presidentes eleitos derrubados por uma combinação de protestos populares e intervenção militar. Embora exista um espírito capitalista na costa e na selva, na região andina, à semelhança dos casos peruano e boliviano, predomina uma cultura anticapitalista. No entanto, é um país atípico por ter o dólar como moeda nacional e muitos de seus cidadãos (um décimo da população) morando nos Estados Unidos. A explosiva fragilidade fiscal foi contida nos últimos anos pelo aumento do preço de petróleo (principal produto 
de exportação) e a dolarização. O populismo é estrutural no país, sendo desta vertente os principais candidatos nas últimas eleições presidenciais.

$\mathrm{Na}$ Bolívia, reformas pró-mercado implementadas em fins da década de 1980 possibilitaram uma estabilidade econômica e política desconhecida na história prévia. Mas o país foi aprofundando sua divisão: a região leste com sua cultura empreendedora conseguiu nos últimos 15 anos um alto e continuado crescimento econômico, o altiplano preso a uma cultura introvertida e estatista permaneceu estagnado (MAYORGA, 2005). O conflito entre as duas Bolívias eclodiu em 2003, quando se desenvolveu no altiplano um forte movimento popular, indigenista e nacionalista, contrário a um projeto de investimento estrangeiro em grande escala para exportar gás natural para o Chile e liquefeito para EUA e México, que teria mudado irreversivelmente a correlação de forças em favor do leste capitalista. A partir do triunfo de Evo Morales nas eleições de 2005 e a conseqüente implementação de uma política estatista populista (nacionalização das indústrias de petróleo e gás, reforma agrária, aliança com o regime chavista) e da tentativa em curso de estabelecer uma república indígena, a Bolívia tornou-se um país à beira da guerra civil e da desintegração.

O Paraguai é um país baseado na economia do ilícito: contrabando, roubo de propriedade industrial e intelectual, tráfico de drogas e armas, e lavagem de dinheiro. De fato, o Paraguai é um precursor mundial de Estados fracassados. Já na década de 50 o ditador Stroessner reorganizou o Estado com eixo no contrabando e no personalismo, criando uma máquina política clientelística poderosa em torno do Partido Colorado, que durou até 2008, quando foi derrotada por uma coalizão populista de esquerda liderada pelo ex-Padre Lugo. O país possui uma das rendas per capita mais baixas da região e os fatores de modernidade econômica estão associados à presença brasileira (Itaipu Binacional e agronegócios brasileiros). Um fator potencial de desestabilização do país constitui a presença na tríplice 
fronteira (Ciudad del Este) de comunidades xiitas ligadas ao Hezbollah, o qual tem levado à presença militar e de inteligência dos EUA no país.

Guiana e Suriname são países pequenos, de pobreza estendida, onde o Estado de Direito é muito limitado. O segundo é um Estado falido, instável politicamente e base muito importante do ilícito transnacional (com grande contrabando de armas para a região vindas de Rússia, China e Líbia). No outro extremo, cabe destacar a Guiana Francesa, que mesmo não sendo um país soberano por ser uma província de ultramar, exibe uma das melhores rendas per capita da região. Entre os territórios do ecossistema amazônico, o que está sob controle da Guiana Francesa exibe o maior Estado de Direito. O destino deste país, comparado com as Guianas que se tornaram independentes, mostra as vantagens da interdependência com os países desenvolvidos, assim como os riscos de processos de libertação nacional marcados por voluntarismos utópicos.

Em termos da problemática da América do Sul, deve ser observado que o debate público e acadêmico está muito contaminado por componentes anti-capitalistas que concebem a criação de riqueza não como o resultado de ações individuais auto-interessadas, típica do liberalismo, mas sim como derivada da ação do Estado. Este é visto como um ente coletivo capaz de agir de forma benevolente em nome dos interesses de longo prazo de toda a coletividade, o que requer uma interpretação dos próprios agentes públicos como elementos puramente altruístas. É freqüente a referência à vontade política como variável necessária e suficiente para a consecução de ações e obtenção de resultados, desconsiderando as restrições políticas e econômicas existentes na própria dinâmica social.

No terreno propriamente econômico, esta percepção voluntarista expressa uma visão católica tradicional (de fundamento moral-ético) sobre o papel da acumulação de capital, da concessão de crédito e das atividades de investimento, típicas de uma economia de mercado e essenciais ao seu efetivo funcionamento. A opinião pública se caracteriza, portanto, pela baixa capacidade de compreender o papel do risco como elemento inerente ao investimento capitalista, por um lado, 
e o papel do setor financeiro e de suas inter-relações com as empresas, por outro. A lógica coletivista (o Estado produz a riqueza que deve ser distribuída pela sociedade) se transforma num processo legislativo de concessão de direitos e garantias ideais. Isso implica uma percepção equivocada da realidade posto que, de um lado, minimiza a escassez dos recursos públicos e, de outro, desconsidera que tais recursos são resultado da taxação dos cidadãos, limitando, por assim dizer, a sua capacidade de agir responsável e autonomamente em prol de seus desejos e necessidades. A dificuldade em aceitar a finitude dos recursos públicos como um dado da realidade também se expressa na defesa cega de políticas de desenvolvimento que quase sempre desconsideram seus custos para a sociedade, algo que os economistas chamam de custos de oportunidade. A aceitação generalizada de uma opção por políticas industriais - dinheiro escasso sendo destinado aos grupos mais ricos da sociedade - é um bom exemplo deste tipo de distorção (VIOLA e PIO, 2004).

A noção liberal de que o papel essencial do Estado é criar e garantir regras simples, universais e impessoais, que expressem os costumes vigentes, é estranha ao universo sul-americano com exceção do Chile (VARGAS LLOSA, 2005). O processo legislativo busca garantir ideais distantes da sociedade, criando um universo ficcional que acaba por ser aplicável de maneira limitada, parcial e relativa. Isto reforça a disposição dos cidadãos de avaliar a funcionalidade ou mesmo o caráter justo/justificável de uma dada legislação, operando de maneira cínica e transgressora em relação às regras. A transgressão da norma, ou, de forma mais geral, da ordem, Ihes parece aceitável e, em alguns contextos, justificável, particularmente quando realizada pelos que são vistos como mais fracos. Em termos de uma sociedade capitalista moderna, esses elementos são especialmente problemáticos porque elevam o risco e a incerteza dos investimentos na medida em que corroem a garantia de direitos de propriedade e a validade de contratos de longo prazo, e dificultam o processo de execução de dívidas. 


\section{Genealogia do populismo}

No meio de um ciclo de democratização ainda não consolidado, começado nos anos 80 do século passado, a América do Sul registra uma presença cada vez mais forte do populismo e um conseqüente retrocesso político (BOTANA, 1998; GRONDONA; 1999; SCHMITTER, 2006). Este fenômeno ocupa quase todo o cenário político na Venezuela de Chávez, na Bolívia de Morales, no Equador de Correa e na Argentina de Kirchner. Embora em bastante menor grau, ameaça também o futuro de países como Peru e Brasil. Por certo, o populismo não é algo novo na América Latina, mas a atual onda tem componentes singulares que não podem passar despercebidos ao observador. $O$ fracasso das experiências populistas anteriores na região, assim como suas características antidemocráticas, não permitiam suspeitar uma nova emergência no atual contexto democrático. Mas algo aconteceu que fez possível este anacronismo. Embora o populismo continue respondendo à mesma lógica contrária à democracia do passado, ele se apresenta hoje com outra cara aparentemente mais atrativa. Levar em conta esta transformação resulta essencial na hora de querer entender a realidade atual.

Outrora repudiado pelos nomes mais representativos do pensamento democrático (tanto da esquerda como da direita), devido à sua forte carga autoritária associada de forma inegável a setores reacionários do militarismo latino-americano (como entender a um Vargas e a um Perón sem esses componentes?), o populismo retorna hoje prestigiado pelas urnas da democracia e com seu passado praticamente esquecido. Como um claro sintoma dos novos tempos, são cada vez mais os autores que derramam seus óleos sagrados sobre este fenômeno - como é o caso do livro A Razão Populista (LACLAU, 2005). Assim, o retrocesso possui duas caras: com o mesmo ímpeto que o populismo ganha votos num grande número de países da América Latina, também pretende ganhar legitimidade ideológica no campo democrático. Resulta difícil saber o que é pior, já que nada poderia ser tão prejudicial para os processos de consolidação democrática em 
andamento no continente do que confundir a democracia com o populismo.

Embora o fenômeno do populismo não fosse analisado com esse nome por Hannah Arendt, sua emergência está associada aos processos que a filósofa alemã descreveu como deterioro do espaço público nas sociedades pluralistas quando se tornam sociedades de massa (ARENDT, 1973). O elogio do populismo não se apresenta hoje justificado pelos mesmos argumentos antidemocráticos do passado. Pelo contrário, o que preocupa atualmente é sua retórica aparentemente democrática. A história do populismo latino-americano pode ajudar a entender melhor este ponto. Ele sempre apareceu associado ao apoio de grandes massas da população, mas nunca foi pensado como ferramenta para a construção das bases da democracia política, como se está pretendendo fazer agora. No antigo populismo, a questão da democracia política nunca foi central. Os populismos de Vargas ou Perón, por exemplo, foram construídos como reivindicação de direitos sociais, antes que políticos. Mais ainda, muitas vezes os golpes militares na América do Sul foram realizados como reação a experiências e lideranças populistas vividas pelas elites e opinião pública democrática como ameaças às instituições republicanas. As lideranças populistas sul-americanas sempre tiveram um perfil caudilhesco derivado da tradição ibérica e da influência dos fascismos (italiano, espanhol, português e alemão). Franco, grande figura inspiradora de Perón, auto-definiu seu cargo, em 1939, como: "Caudillo de España por la Gracia de Dios".

O elogio atual do populismo reconceitualiza o fenômeno em termos das supostas excelências de sua racionalidade política. Agora, o populismo aparece querendo construir a democracia, fazendo ingressar os excluídos no sistema político democrático. Por certo, o grande desafio da democracia é a inclusão dos habitantes de toda a nação enquanto cidadãos. Mas será que o populismo cria cidadania? Será que os processos políticos detonados por lideranças como Perón, Vargas, Chávez, Morales e Kirchner são geradores de cidadãos?

Já nos anos 30 do século XX, o filósofo Leo Strauss criticava o jurista Carl Schmitt por dar-Ihe preeminência política à noção de inimigo 
e, portanto, à lógica da guerra (STRAUSS, 1996). Quando o comportamento político dos atores reproduz esta lógica a nação acaba, mais cedo ou mais tarde, esfacelada em fatias irreconciliáveis; o qual, por sua vez, conduz a uma perigosa deterioração da governabilidade que deixa os indivíduos indefesos enquanto cidadãos. No final de um caminho semeado de inimigos se encontra a ditadura como única saída possível para o restabelecimento da ordem. Apesar do século XX registrar no mundo uma longa série de resultados catastróficos derivados dos movimentos e processos políticos guiados por essa lógica, poucos ensinamentos neste sentido parecem ter sido assimilados na América Latina. As tentativas de produzir transformações sociais e políticas que apontem a melhorar a vida dos indivíduos são absolutamente válidas. Nem conservadores, nem revolucionários, podem discordar disto. A política se legitima na tentativa de mudar a realidade para melhor. Mas o verdadeiro ponto de inflexão não reside nos fins propostos, senão nos limites que os atores devem definir e adotar para que a política alcance tais fins. A política supõe certo grau de inimizade e de mentira entre os atores que disputam o mesmo espaço, sem dúvida. Mas desde uma perspectiva democrática os atores que constroem e consolidam a democracia precisam evitar tanto a exacerbação do cinismo, como da inimizade. O repertório populista nem sempre é o mesmo. Às vezes, seu cardápio traz mais cinismo que inimizade, ou vice-versa, mas as conseqüências deletérias para a democracia são parecidas.

O fenômeno populista emerge e se fortalece quanto mais avança na direção de extremos onde a preeminência das lógicas do cinismo e do inimigo se impõem. O populismo atenta contra a sustentabilidade da democracia e do desenvolvimento porque estes são viáveis, basicamente, a partir de uma lógica onde Estado, sociedade civil e mercado definem espaços de convivência e de relativa confiança entre os diversos atores (ARENDT, 1959; PEYREFITTE, 1999). Lembrando os anos 60, Roberto Campos assinalava que América Latina era terra fértil para o surgimento de dois protagonistas funestos para o sadio desenvolvimento da democracia: um, o demagogo e, o outro, o 
extremista (CAMPOS, 1994). Ambos os atores pretendendo resolver todos os problemas com fórmulas sedutoras e rápidas. Uma notícia boa das últimas décadas é que a ampla maioria dos atores políticos do continente reivindica a idéia de democracia; mas, em compensação, a notícia péssima é que esses dois atores que antes agiam contra a democracia por separado, agora estão juntos. Uma das circunstâncias mais tristes de América Latina é a atual convergência democrática de demagogos e radicais, fruto do fracasso histórico da revolução socialista no mundo.

Para os populistas é fácil ser sedutores: eles gastam recursos sem qualquer eficiência produtiva e culpam aos outros quando a festa acaba. Em todas as suas variantes, o populismo sempre foi contrário à economia de mercado. Para pior, vende a imagem de que as riquezas são um fruto mágico da nação que o Estado deve apenas administrar com justiça. Desse modo, resulta fácil cair nas redes da sedução, já que ninguém parece ter que fazer um esforço maior para melhorar de vida. Obviamente, se algo vai mal a culpa será do capitalismo e do imperialismo! O resultado previsível no curto ou longo prazo é a degradação da democracia e a infelicidade da nação. As promessas da democracia são de procedimento, apontam principalmente a garantir as liberdades econômicas e políticas. A rigor, a receita populista conduz os países ao fracasso porque centraliza todas as decisões econômicas e políticas. Num país como a Venezuela de Chávez, onde o Estado monopoliza o petróleo da mesma forma que a opinião pública, não há lugar nem para o crescimento da economia, nem dos cidadãos. Pelo contrário, as promessas da democracia não giram em torno de benesses oferecidas pelo Estado com passes de mágica, senão do oferecimento de igualdade de oportunidades para os cidadãos cuidarem de seu destino de acordo com seus méritos. A democracia pode se tornar sedutora quando confrontada com a ditadura. Mas a América do Sul já não tem como continuar justificando a democracia em função de regimes ditatoriais que aconteceram mais de duas décadas atrás. Aqueles que maquiam a democracia com as soluções fáceis do populismo estão, a rigor, degradando a democracia para seus fins particulares. 
A diferença do antigo com o novo populismo é que o primeiro não prejudicava a democracia com seu fracasso (a qual, de fato, se constituía em sua alternativa). Mas hoje as coisas são diferentes, as experiências populistas afetam negativamente às democracias que as albergam. As promessas de solução integral dos problemas da nação de forma imediata implicam, quando da chegada do populismo ao governo, uma segura violência contra o sistema institucional estabelecido. O radicalismo das promessas obriga esses governos a queimar etapas a fim de justificar sua existência no curto prazo entre uma eleição e outra. $\mathrm{E}$ o que acontece com a cidadania quando se ressentem e banalizam as instituições? No limite, acontece cidadania zero e exclusão total. O populismo quer incluir as massas dentro do sistema político sem criar cidadania, sem criar consensos em torno dos verdadeiros procedimentos para encontrar soluções para os problemas econômicos e políticos. A falsificação democrática do populismo reside aqui: não cria cidadania senão maiorias desprovidas de consciência ao serviço das elites de turno (tudo às custas das instituições democráticas e do dinheiro dos contribuintes). Os excluídos merecem ingressar pela porta no sistema político, não pela janela. A inclusão populista não sobrevive ao passo do tempo porque ela apenas promove o clientelismo político das massas. A emergência do populismo muitas vezes encontra sua justificação nas crises da democracia, mas as promessas que elevam os populistas até o governo nunca se referem ao aperfeiçoamento das instituições. Pelo contrário, a radicalização populista da democracia se constrói contra os direitos dos indivíduos e as regras do livre mercado. Infelizmente, a democracia é uma construção que não sobrevive à fragilização das leis e das instituições. A rigor, no longo prazo, sem um bom Estado e um bom mercado, não há democracia possível.

Os cidadãos estão obrigados a serem realistas, porque com a utopia não se garante o aumento da produtividade da economia nem um Estado eficiente, neutral e previsível. Neste sentido, se existe algo que os populistas não sabem nem querem fazer é cuidar do Estado. Para eles, o Estado é sempre um botim de guerra! Isto não deveria estranhar a ninguém. Sendo a lógica da guerra que conduz os movimentos 
populistas ao poder, o Estado só pode ser enxergado como patrimônio do vencedor. A entronização do assistencialismo clientelístico e de uma tributação excessiva, assim como a multiplicação dos cargos de confiança para os militantes, a apropriação indevida de recursos e outros casuísmos e violências jurídicas, destinados à perpetuação no poder, são evidências de que o avanço do populismo está intimamente associado à decadência do Estado e do livre mercado. Quanto mais fracas são as instituições de um país, mais exposto ele fica à aventura populista. Quanto mais avança o populismo, mais se enfraquecem as instituições.

O populismo não é um regime, nem se define por conteúdos únicos nos planos econômico, político e social. O sentido do populismo se condensa no caráter degradante de suas manifestações, as quais são múltiplas e de diferente capacidade de ação e conseqüências. No entanto, apesar desta diversidade de manifestações, o populismo baseia sua ação em alguns pressupostos gerais ideológicos e epistemológicos que vale a pena revisar.

O populismo opera com uma mecânica baseada num determinismo empobrecedor da visão da realidade. A este respeito, a primeira coisa que chama a atenção é que as visões deterministas tenham se reproduzido na sociedade moderna, ocultando seu parentesco com as doutrinas teleológicas antigas e medievais da predestinação e do fatalismo. Os determinismos baseados em leis naturais surgem da mesma matriz que esses teleologismos. Em ambas as expressões se postula um encadeamento rigoroso dos fenômenos que excluem qualquer possibilidade de liberdade ou contingência. A diferença é apenas de roupagem, enquanto os determinismos modernos se cobrem com o manto da ciência, os teleologismos antigos se cobriam com o da religião ou da metafísica. Mas as conseqüências de seus supostos são as mesmas. Em sua ambição de explicar os fenômenos por completo, são obrigados ao reducionismo (já que, quanto maior a complexidade, menor a percepção de que existe uma relação estrita de causa-efeito), assim como ao imediatismo (já que os processos de longa 
duração aumentam a percepção da contingência, na mesma proporção que, os de curta duração, os de certeza).

Nem a boa ciência, nem a boa teologia, derivam da matriz determinista, mas não é isso o que importa aqui. De fato não haveria maiores problemas se esta questão ficasse restrita ao campo da ciência e da religião. Mas acontece que, através das ideologias políticas, o determinismo extrapolou suas origens, colonizando progressivamente a política. Sabemos que, na sociedade moderna, as ideologias se transformaram em armas poderosas das elites (sejam proletárias, burguesas, militares ou indígenas) para chegar ao poder, assim como para se manter nele. Mas o que torna tão poderosas as ideologias não é tanto elas anunciarem um mundo repleto de coisas boas para os cidadãos, senão o fato de anunciarem isto com uma retórica determinística simplificada, fácil de acessar pela massa. Isto é, uma ideologia não atrai tanto às massas pelo seu conteúdo, mas pela sua forma. Se ela não oferecer crenças garantidas pelo senso comum, ela não funciona como ideologia.

Resulta curioso que algumas ideologias se atribuam base científica, levando em conta que a ciência, pelo contrário, não se constrói a partir de crenças, senão de críticas. A ciência é uma tarefa essencialmente autocorretiva, nunca definitiva, portanto incapaz de garantir qualquer resultado independentemente da experiência. No campo científico as coisas podem ser explicadas de uma maneira hoje e de outra amanhã. Mas a ideologia não se alimenta de variações senão de certezas, por isso ela abraça o determinismo com paixão. Por isso, ainda no caso de que comecem bem, depois de um tempo as ideologias passam a ser como óculos de cego: mais que uma ajuda para ver a realidade elas servem para ocultar a cegueira. São os desejos do sujeito os focalizados pelas ideologias, não a dinâmica da realidade. Desejos que obtêm sua realização extrema no caso dos mitos, tão comuns na história de América Latina (VARGAS LLOSA, 2006). E a natureza humana, quando não devidamente preparada por uma experiência sábia, tende a querer que tudo seja dado da forma mais fácil e imediata possível. Assim, quanto mais a política se aproxima do nível da massa, 
maior o benefício instrumental para os atores (populistas) se usarem de ideologias de base determinista. A rigor, o determinismo (junto ao fatalismo) são as principais formas de conhecimento que conduzem ao senso comum da massa.

Apesar do amplo reconhecimento da teoria de Darwin, ainda hoje o senso comum pensa que as girafas têm pescoços cumpridos de tanto espichar os mesmos para alcançar as folhas nos topos das árvores. Sem dúvida, isto deriva do fato desta explicação ser a mais fácil de todas as disponíveis. Na visão de Darwin não são as girafas os sujeitos (ou artífices) do comprimento de seu pescoço, a explicação é muito mais complexa (SPRINGER DE FREITAS, 2003). O pescoço longo é o resultado de mutações objetivas, que nada têm a ver com as intenções particulares de um ou de outro animal. As girafas têm pescoço longo porque aquelas que nasceram com ele assim tiveram mais chance de sobreviver no meio em que viviam (ao alcançar melhor o topo das árvores). Portanto, serão as sucessivas proles (as quais logicamente estarão herdando um pescoço longo) que darão essa marca à espécie. Da mesma forma opera o senso comum quando pensa, por exemplo, que o crime é culpa da pobreza, não percebendo que o crime talvez seja uma das circunstâncias mais complexas da condição humana civilizada. No crime se registra uma desobediência da lei, tanto quanto a necessidade de um castigo reparador que mostre a todos (sociedade e criminosos) o verdadeiro caminho. Exceto em casos patológicos, a condição de criminoso é uma opção do indivíduo, num contexto social, político e cultural onde ele verifica que o crime compensa mais que a obediência à lei, dada a falta de castigo reparador (isto é, igual ao caso das girafas, se aqueles cidadãos que possuem as mãos mais compridas começam a se dar bem na vida, o futuro trará mais proles com essas características). O crime não é resultado da pobreza do indivíduo (até porque, se assim fosse, os ricos e as elites não cometeriam crimes, quando o que se vê não é bem isso), senão um resultado sistêmico da forma que Estado e sociedade entendem e respondem ao crime. Portanto, não é a nivelação da riqueza entre os cidadãos que vai dar resposta ao crime, senão o cumprimento severo das regras do Estado de 
Direito e a sintonia espiritual coletiva da nação (o qual implica, entre outras coisas, transcender os particularismos subjetivos dos atores, uma revisão do elitismo dos procedimentos judiciais para que os criminosos de colarinho branco também sejam enviados para a prisão, assim como a urgente construção de prisões para que traficantes e corruptos fiquem em prisões comuns dignas e seguras). A teoria da girafa que estica seu pescoço é fácil de entender porque reduz uma questão altamente complexa a uma única causa bem simples, construída a partir de desejos voluntaristas dos sujeitos. As explicações que atribuem a culpa de qualquer coisa à pobreza são do mesmo tipo. Reduzir todos os males à pobreza (assim como a causa desta às elites ou ao capitalismo) é algo funcional aos desejos voluntaristas das massas, que as libera tanto de qualquer responsabilidade moral como do esforço conceitual necessário para compreender sua situação.

$\mathrm{Na}$ América Latina, os regimes autoritários têm se apoiado historicamente em ideologias políticas também de base determinística. Mas, paradoxalmente, com a chegada da democracia nos anos 1980 este aspecto não tem diminuído, senão aumentado. Quando os cidadãos sofriam os autoritarismos de turno imaginavam que com a democracia a coisa seria diferente. A democracia, supostamente, deveria trazer pluralismo de idéias ao jogo político e facilitar a criação de consensos mais sofisticados sobre os diversos problemas. No entanto, o que tem acontecido é que a democracia está contribuindo para a simplificação dos problemas. Para atrair o voto dos cidadãos os atores políticos acabaram apelando para ideologias de fácil compreensão que podem chegar a barbarizá-los, paradoxalmente, muito mais que o ostracismo a que estavam submetidos antes, durante o regime autoritário. No passado, as ideologias dos atores latino-americanos se diferenciaram bem. Existiam liberais e socialistas, revolucionários e conservadores, e esses atores sustentavam ideologias sofisticadas que não reduziam os problemas a causas simples de resolução imediata. Embora tomadas individualmente essas ideologias estivessem marcadas pelo determinismo (não existe ideologia política sem o componente 
determinístico, como já foi dito), todas explicavam a realidade a partir de visões relativamente mais complexas do que as de hoje.

No marco das democracias populistas que assolam a América Latina, o liberalismo e o socialismo tendem a degradar-se com receitas rápidas e fáceis de aplicar. Por exemplo, em contraste com o liberalismo clássico, o neoliberalismo, em boa medida, se tornou economicista (reducionista para o econômico), e o neo-socialismo, em maior medida ainda, se tornou societalista (reducionista para o social). Essas ideologias, que nasceram vinculando política, sociedade, economia, direito e cultura de uma forma relativamente sofisticada, nas últimas duas décadas se tornaram visões que radicalizaram ao extremo seu reducionismo e imediatismo potencial, depreciando o fortalecimento da consciência dos cidadãos e das instituições políticas, legais e culturais. Esta é a explicação para o avanço do populismo que de norte ao sul do continente pipoca pela maioria dos países. Esta ideologia é a que melhor encarna a simplificação e a banalização da realidade. Através do populismo é que convergem hoje para um destino comum os neosocialismos e os neoliberalismos. Como essa aberração foi possível? A resposta é porque a democracia se instalou em países com baixa exigência espiritual de responsabilidade individual e coletiva, associada a uma cidadania historicamente dissociada do cumprimento da lei. Nesse contexto, as ideologias que tinham conseguido preservar certos graus de complexidade dentro de núcleos reduzidos de cultores (em função da situação de restrição democrática, que impedia aberturas maiores para qualquer ideologia), com a chegada da ampliação democrática irrestrita começaram a ser rapidamente simplificadas para poder circular entre as massas na forma de marketing ideológico (tanto para criticar como para louvar).

Além da relação de empatia servil que se estabelece entre as massas e o líder, o populismo está sempre acompanhado de uma retórica determinística que se situa o mais longe possível de um uso da liberdade baseado na responsabilidade. Sejam neoliberais ou neosocialistas, os populismos convergem por caminhos tortos por conta de sua mágica de suprimir o tempo de espera da política num cenário 
simplificado onde, a rigor, vale tudo para o populista de turno (mesmo a transgressão da lei). Os tempos da construção política e cultural dos países não são subjetivos, senão objetivos; eles são sempre longos, sendo essa dinâmica de longo prazo o que os torna sólidos. Mas se as soluções são simples e exigidas para já, não haverá boa política, nem boa cultura, que possam ser condensadas no Estado de Direito, nem nos corações e mentes dos cidadãos. O maior perigo hoje, na América Latina, não é o imperialismo, nem os militares, nem mesmo os revolucionários, os bandidos ou os corruptos. O maior perigo é o populismo que cultua a pobreza, se despreocupando de convocar os cidadãos para a responsabilidade individual e o trabalho produtivo, assim como para a construção da comunidade política e o Estado de Direito. Nas atuais circunstâncias, este estado de coisas não se combate apelando a outras ideologias supostamente melhores, se combate colocando em evidência a mediocridade e perigo das raízes simplificadoras, reducionistas, imediatistas, des-responsabilizadoras e ególatras (auto-centradas nos desejos dos sujeitos), das ideologias em geral, que resulta tão funcional à maioria dos atores políticos atuais para manipular a massa e destruir, de passo, à nação.

Como quebrar o círculo vicioso do populismo? Defendendo os princípios da liberdade e da responsabilidade. O populismo assume uma retórica determinista porque assim as coisas sempre seguem um rumo, no qual os atores nunca são responsáveis pelo seu destino. A história está longe de ser o reino da cega necessidade pregada pelo determinismo, como queria Marx. Com a derrubada do Muro de Berlim em 1989, e a estrepitosa decadência das experiências revolucionárias do socialismo e do comunismo, ficou claro para qualquer observador isento de preconceitos que, pelo contrário, a história é o reino da liberdade. Tanto no sentido do indeterminado de seu resultado final, quanto nos fatores que constituem o agir humano. Em seu sentido mais forte, a liberdade é a base da democracia e do desenvolvimento. A chamada liberdade política é um componente necessário, mas não suficiente, para constituir plenamente a democracia. Na linha do pensamento clássico de John Stuart Mill, a democracia liberal exige também a liberdade do 
indivíduo para agir de acordo com sua própria consciência, de escolher seu caminho com autonomia (MILL, 1997). Como pedia Kant, isto exige sair da minoridade, pensar por conta própria (KANT, 1988). Não existe liberdade sem responsabilidade. Quem não paga pelas conseqüências de seus atos nunca aprenderá a fazer bom uso da liberdade. Talvez a maior coragem e virtude exigida nos tempos difíceis seja esta, a de indivíduos e sociedade assumirem os custos da liberdade. A fonte de inspiração para isto talvez seja espiritual.

Héctor Ricardo Leis é doutor em Filosofia pela Pontifícia Universidade Católica do Rio de Janeiro (PUC-Rio) e professor associado do Departamento de Sociologia e Ciência Política da Universidade Federal de Santa Catarina (UFSC).

E-mail: hector.leis@gmail.com

\section{Referências:}

ARENDT, Hannah. The Human Condition. New York: Anchor Book, 1959. . The Origins of Totalitarianism. New York: HBJ Book, 1973.

BEJARANO, Ana Maria; PIZARRO, Eduardo. From Restricted to Besieged: the changing nature of the limits to democracy in Colombia. In: HAGOPIAN, Frances; MAINWARING, Scott P. (Eds.). The third Wave of Democratization in Latin America: Advances and Setbacks. Cambridge: Cambridge University Press, 2005. p. 235-260.

BOTANA, Natalio Rafael. El siglo de la libertad y el miedo. Buenos Aires: Ed. Sudamericana, 1998.

CAMPOS, Roberto. Lanterna na Popa. Rio de Janeiro: Topbooks, 1994.

COPPEDGE, Michael. Explaining Democratic Deterioration in Venezuela through Nested Interference. In: HAGOPIAN, Frances; MAINWARING, Scott P. (Eds.). The third Wave of Democratization in Latin America: Advances and Setbacks. Cambridge: Cambridge University Press, 2005. p. 289-316.

GRONDONA, Mariano. Las Condiciones Culturales del Desarrollo Econômico. Buenos Aires: Ariel, 1999. 
KANT, Immanuel. Resposta à pergunta: O que é o Iluminismo? In: . A paz perpétua e outros ensaios. Lisboa: Edições 70, 1988. p. 11-19.

LACLAU, Ernesto. La razón populista. Buenos Aires: FCE, 2005.

MAYORGA, Rene. Bolivia's Democracy at the Crossroads. In: HAGOPIAN, Frances; MAINWARING, Scott P. (Eds.). The third Wave of Democratization in Latin America: Advances and Setbacks. Cambridge: Cambridge University Press, 2005. p. 149-178.

MILL, John Stuart. Sobre a liberdade. Lisboa: Publicações EuropaAmérica, 1997.

O'DONNEL, Guillermo. Poliarchies and the (Un)Rule of Law in Latin America. In: MÉNDEZ, Juan; O'DONNEL, Guillermo; PINHEIRO, Paulo Sérgio (Eds.). The (Un)Rule of Law and the Underprivileged in Latin América. Notre Dame: Notre Dame University Press, 1999. p. 303-337.

PEYREFITTE, Alain. A Sociedade de Confiança. Rio de Janeiro: Topbooks, 1999.

SCHMITTER, Philippe. Sobre los vicios y virtudes del populismo. El debate político - Revista Iberoamericana de Análisis Político, Buenos Aires, Ano 3, n. 4/5, p. 208-215, 2006.

SPRINGER DE FREITAS, Renan. Sociologia do Conhecimento, pragmatismo e pensamento evolutivo. Bauru: EDUSC, 2003.

STRAUSS, Leo. Apuntaciones sobre 'el concepto de lo político' de Carl Schmitt. In: Persecución y arte de escribir. Valencia: Edicions Alfons el Magnànim, 1996. p. 54-75.

TALAVERA, Arturo Fontaine. Tendências à globalização no Chile. In: BERGER, Peter L.; HUNTINGTON, Samuel P. (Orgs.). Muitas Globalizações - Diversidade Cultural no Mundo Contemporâneo. São Paulo: Record, 2004. p. 285-330.

TANAKA, Martin. Peru 1980-2000: Chronicle of a Death Foretold. In: HAGOPIAN, Frances; MAINWARING, Scott P. (Eds.). The third Wave of Democratization in Latin America: Advances and Setbacks. Cambridge: Cambridge University Press, 2005. p. 261-288.

VARGAS LLOSA, Alvaro. Liberty for Latin America: How to Undo Five Hundred Years of State Oppression. New York: Farrar, Straus \& Giroux, 2005.

The Che Guevara Myth and the Future of Liberty. Washington: Independent Institute, 2006. 
VIGEVANI, Tullo; OLIVEIRA, Marcelo Fernandes de. América Latina: vulnerabilidad social e instabilidad democrática. In: DUPAS, Gilberto (Org.). América Latina a comienzos del siglo XXI. Perspectivas económicas, sociales y políticas. Rosario: Homo Sapiens Ediciones, 2005. p. 193-253.

VIOLA, Eduardo; LEIS, Héctor Ricardo. Sistema Internacional com Hegemonia das Democracias de Mercado: Desafios de Brasil e Argentina. Florianópolis: Editora Insular, 2007.

VIOLA, Eduardo; PIO, Carlos. Doutrinarismo e Realismo na Percepção do Interesse Nacional no Brasil. In: OLIVEIRA, Marcos Guedes de (Org.). Brasil e EUA no Novo Milenio. Recife: Editora da Universidade Federal de Pernambuco, 2004. p. 13-42.

WHITEHEAD, Laurence. Latin América - A New Interpretation. Londres: Palgrave Macmillan, 2006. 